\title{
cento e vinte anos de produção mundial de açúcar: comentário sobre séries estatísticas tradicionais (1820-1940)
}

Heitor Pinto de Moura Filho

Universidade Federal do Rio de Janeiro

\section{RESUMO}

Seja qual for a abordagem historiográfica adotada, existem cuidados preliminares no uso de séries estatísticas que não podem ser relegados a segundo plano. Pinçar séries prontas, em fontes secundárias aparentemente confiáveis, pode revelar-se perigoso. Este texto compara algumas séries de produção mundial de açúcar, amplamente difundidas na bibliografia sobre o século XIX e a primeira metade do XX. Identifica dificuldades genéricas das estatísticas açucareiras e expõe discrepâncias e convergências entre 8 séries, cobrindo o período de 1820 a 1940 . Refere-se essencialmente a problemas decorrentes de diferentes unidades de medida, da existência de diversos tipos de açúcar e de abrangências geográficas heterogêneas. Uma genealogia de valores entre as séries se torna aparente. Alguns erros nas séries publicadas também são identificados.

Palavras-chave: açúcar, estatísticas econômicas, medidas, cana-de-açúcar, beterraba açucareira

\begin{abstract}
Whatever the historiographic attitude adopted, there are certain precautions preliminary to the use of statistics, which cannot be abandoned. To extract readymade series from apparently trust-worthy secondary sources may turn out to be a dangerous procedure. This text compares series ofworld sugar production common1y found in bibliographies on the nineteenth and early twentieth century. It identifies generic difficulties in sugar statistics and exposes the discrepancies and convergences of 8 series, covering the period from 1820 to 1840 . Reference is made to problems created by different measurement units, by the existence of various types of sugar and by series with heterogeneous geographical áreas. A genealogy of values among the series becomes apparent. A few errors in published series are also identified.
\end{abstract}

Key words: sugar, economic statistics, measures, sugar-cane, beet-cane

Desde que os historiadores passaram a considerar uma série estatística como objeto lícito para suas investigações, muito se escreveu sobre o que eram ou deviam ser tais séries, sobre sua validade e seus limites na

Uma primeira versão deste trabalho foi apresentada no V Congresso Brasileiro de História Econômica e na $6^{a}$ Conferência Internacional de História de Empresas, Caxambu (setembro/2003).E-mail: heitormoura@yahoo.com.br 
análise histórica. A distinção entre seu emprego em história, por historiadores, e nas demais ciências sociais, por seus respectivos profissionais, rendeu polêmicas e posicionamentos aguerridos. Seja qual for a abordagem adotada, entretanto, existem cuidados preliminares comuns, que não podem ser relegados a segundo plano, pois o longo caminho entre a construção de séries primárias e sua interpretação — segundo a predileção analítica de cada estudioso - é repleto de obstáculos e armadilhas. Pinçar séries prontas, em fontes secundárias aparentemente confiáveis, pode revelar-se ainda mais perigoso.

Neste texto, propomo-nos a comparar algumas séries estatísticas sobre a produção mundial, amplamente difundidas na bibliografia relativa à história açucareira do século XIX e da primeira metade do XX. Ao expor dificuldades para sua utilização, além de discrepâncias e convergências entre elas, esperamos auxiliar os que quiserem fazer uso destas informações, acautelando todos para o aproveitamento mais seguro de fontes que se impõem com a aparente solidez de monumentos esculpidos em pedra.

\section{Dados quantitativos}

Não há como negar que os dados numéricos, pela sua própria precisão nominal ("257" não é "258", nem tampouco "257,1"), induzem o leitor a lhes imputar uma precisão de representação que nem sempre (ou mesmo raramente) corresponde à verdade. Como a informação quantitativa é usualmente apresentada em conjuntos, quase sempre classificados em categorias ("açúcar de cana","açúcar de beterraba","açúcar exportado", "açúcar vendido no mercado interno", para ficarmos no setor), esta precisão nominal parece reafirmada pela especificidade das categorias. Sendo, além disto, disposta numa série cronológica, adquire a força adicional do elo diacrônico que assalta a imaginação do leitor, ao passar os olhos pela coluna da esquerda: $1800,1801,1802, \ldots, 1900$ ! Completando a (possível) ilusão, se os dados estiverem sendo lidos num texto escrito há cem anos, a autoridade do documento irá conferir aos números o placet conclusivo, cuja contestação parece inútil.

Devemo-nos precaver contra todos estes cantos de sereias. Identificar e qualificar as limitações das séries históricas é uma preliminar necessária para seu uso em pesquisa. Escrevemos sobre estatísticas açucareiras, mas qualquer estatística merece cuidados semelhantes: quais foram as fontes empregadas na sua montagem? Que universo pretende retratar? Tratase de estatística censitária ou amostrai? Quais os recortes geográficos e 
conceituais? Que unidades de contagem ou medida foram usadas? Houve estimação de alguma variável ou de objetos desconhecidos? Houve agregações de conjuntos menores? Mantiveram-se os critérios para todos os dados? Há omissões? E, mais, abordar estas questões torna-se fundamental para o historiador econômico, que se propõe a resgatar séries, cobrindo períodos ao longo dos quais estas estatísticas foram produzidas por diversas instituições e pessoas, possivelmente com critérios e objetivos heterogêneos.

A quantificação que se espera de estatísticas sobre a produção mundial de açúcar, por exemplo, é simples: quanto foi produzido de açúcar, no mundo, em cada período indicado? As respostas dadas a esta pergunta, ao longo dos últimos 100 anos, contudo, foram as mais diversas.

A história do açúcar - de sua produção, de seu comércio e de seu consumo - é pródiga em armadilhas para o pesquisador que não se aprofundar nas origens e no significado das informações disponíveis. Antes de abordar as séries de produção mais difundidas na historiografia, mencionam-se armadilhas que freqüentemente criam problemas para o estudioso. Decorrem principalmente da heterogeneidade de medidas, da imprecisão e da falta de confiabilidade dos dados, mas também da ignorância sobre fatos relevantes.

\section{Heterogeneidade de medidas}

A primeira armadilha, aparentemente banal, mas capaz de grandes estragos, refere-se ao uso de diferentes unidades ou até de diferente definições para medidas com os mesmos nomes.

Os exemplos são numerosos. Em 1938, Prinsen Geerligs - uma autoridade reconhecida - abriu sua exposição estatística sobre o açúcar de cana no mundo, listando diversas medidas então comumente empregadas na economia açucareira: 13 medidas de área, 4 medidas de volume e 23 medidas de peso. ${ }^{2}$ Voltando a tempos mais remotos, estes números se multiplicam rapidamente, tendo cada país e, muitas vezes, cada cidade, seu conjunto de práticas. O quintal, medida comum a muitos países de origem latina e assemelhado ao hundredweight inglês, variou conforme a tradição de cada local. O Quadro 1 expõe a grande disparidade entre medidas comumente empregadas no comércio do açúcar (principalmente nos séculos XVII e XVIII, mas que também entraram pelo XIX).

Prinsen Geerligs \& Prinsen Geerligs, 1938, pp. x-xi. 
Quadro 1. Medidas utilizadas no comércio do açúcar e sua equivalência em quilos

\begin{tabular}{|c|c|c|c|}
\hline País & Medida & $\begin{array}{l}\text { Equivalência } \\
\text { em quilos }\end{array}$ & $\begin{array}{c}\text { Índice } \\
(\text { Libra inglesa }=100)\end{array}$ \\
\hline DINAMARCA & pund & 0,4960 & 109,3 \\
\hline HOLANDA & pond & 0,4941 & 108,9 \\
\hline \multicolumn{4}{|l|}{ GR Ã - B RET A NHA } \\
\hline — Escócia pré-1707 & pound & 0,4931 & 108,7 \\
\hline $\begin{array}{l}\text { FRANÇA - Paris, Nantes, } \\
\text { Bordeaux }\end{array}$ & \multicolumn{2}{|c|}{ FRANÇA - Paris, Nantes, } & 107,9 \\
\hline ALEMANHA - Hamburgo & pfund & 0,4844 & 106,8 \\
\hline ESPANHA & libra & 0,4601 & 101,4 \\
\hline PORTUGAL & arrátel & 0,4590 & 101,2 \\
\hline $\begin{array}{l}\text { GRÃ-BRETANHA - Inglaterra, } \\
\text { Irlanda }\end{array}$ & pound & 0,4536 & 100,0 \\
\hline \multicolumn{4}{|l|}{ GR Â-B RET A N HA } \\
\hline — Escócia pós-1707 & pound & 0,4536 & 100,0 \\
\hline FRANÇA - Marseille & livre & 0,4079 & 89,9 \\
\hline
\end{tabular}

Fonte: (McCusker 1973:616)

Esta multiplicidade de medidas foi uma constante até o século XX. Ao final do XVIII, um navio de açúcar ainda saía do Caribe inglês com sua carga medida em short hundredweight (de 100 libras, iguais a 45,36 kg cada) e chegava à Inglaterra para ter sua carga pesada, na descarga, em gross hundredweight (de 112 libras, iguais a $50,80 \mathrm{~kg}$ ), ${ }^{3}$ ou seja, a mesma importação constava da documentação de transporte como 100 hundredweights e ficou registrada nos documentos da alfândega inglesa como 89 hundredweights, sem outras indicações esclarecedoras. Até a implantação definitiva do sistema métrico no Brasil, prolongada pelas últimas décadas do século XIX, a nomenclatura de pesos e medidas brasileira propicia numerosas armadilhas para o historiador, pois os mesmos nomes - canada, pipa, alqueire (de volume ou de área) e até libras, arrobas e toneladas - podiam referir-se a diferentes unidades, conforme a tradição observada fosse a portuguesa de Lisboa, as tradições portuguesas de outras regiões ou ainda a inglesa.

Mais recentemente (até meados do século XX), os padrões anglosaxões (inglês e norte-americano) e o métrico se opuseram silenciosamente no uso da palavra "tonelada", freqüentemente empregada sem maiores qualificativos por uns e por outros. Enquanto a tonelada norteamericana de 2.000 libras (short ton) vale 0,907 toneladas métricas, a

McCusker, 1973. 
tonelada inglesa de 2.240 libras (long ton) se refere a 1,016 toneladas métricas. ${ }^{4}$ Uma diferença de $12,1 \%$ para mais ou de $10,8 \%$ para menos. O que parece um detalhe contornável torna-se obstáculo ao se analisarem textos em que o autor, numa rápida nota de rodapé, lembra que "Estas estatísticas foram coletadas de várias fontes (...) Não foi feita qualquer tentativa para corrigir para toneladas inglesas ou métricas", ou ainda ao se lerem quadros estatísticos com uma única menção a "toneladas", sem maiores indicações de qual. Desde o final do século XIX, contudo, é possível encontrar estatísticas sobre produção mundial uniformizadas em toneladas métricas, nos trabalhos de diversos consultores europeus e das organizações internacionais. ${ }^{6}$

A partir do final do século XIX, esta questão adquire gradativamente menor importância, pois as diversas séries de produção, consumo e comércio exterior passaram a ser construídas com atenção estatística profissional, seja por corretores e casas comissárias (Czarnikow, Willet \& Gray), seja por consultores especializados (H.C. Prinsen Geerligs, F.O. Licht, G. Mikusch). A partir de meados do século XIX, os institutos estatísticos nacionais, pioneiramente o cubano e os europeus, dedicaram atenção especial à produção e ao comércio de açúcar. Já no início do século XX, os sucessivos órgãos internacionais dedicados ao setor açucareiro - originados na Comissão Permanente, criada pela Convenção de Bruxelas de 1902 - e os departamentos estatísticos das organizações multilaterais (a Liga das Nações e, depois, as Nações Unidas) passaram a velar pela homogeneidade e pela compatibilização das medidas.

\section{Precisão e confiabilidade dos dados}

Durante séculos, o açúcar produzido foi secado em pães e socado em caixotes (denominados caixas), que passavam a ser a unidade de contagem, tanto para informação estatística, como para a própria tran-

\footnotetext{
Cabe registrar que as próprias definições de libra nos EUA (0,45304 quilos) e no Reino Unido (0,4535925 quilos) eram distintas ejá estão computadas na equivalência das toneladas curta e longa.

Deerr, N. The History of Sugar. London: Chapman \& Hall v.2, 1950, p.499.

F.O. Licht e International Sugar Council. The World Sugar Economy. Structure and Policies. London: International Sugar Council, 1962 e 1962, respectivamente, v. I, 311 pp.,v. 11,351 pp.

Sobre os primórdios dos sistemas estatísticos nacionais, ver Martin, 2001. Sobre estatísticas açucareiras e seus usos comerciais, Moreno Fraginals, 1989:305-44.
} 
sação comercial. Nada era padronizado - o tamanho da caixa, seu peso vazio (tara) e até o tempo em que o açúcar aí estava (e, portanto, quanto tempo tinha tido para secar). Tais informações poderiam ser propositalmente omitidas pelo vendedor ao comprador, como margem para algum ganho adicional.

Além disto, dada a variedade de técnicas e estágios de processamento, conhecer a exata qualidade do açúcar era primordial, fosse para a transação comercial, fosse para efeitos estatísticos.

Produzir com menos gastos de limpeza e refino e conseguir vender este açúcar como de melhor qualidade sempre fizeram parte do jogo de barganha entre produtores, intermediários, refinadores e consumidores. Até o final do século XIX, quando a medição da sacarose se estabeleceu como o padrão nos negócios de açúcar, era problemático identificar que produto estava sendo transportado, comprado e vendido ou tributado. Até esta época, os negócios eram necessariamente concluídos à vista do produto, cuja qualidade poderia ser, assim, aferida pelo comprador ou pelo funcionário. A cor e as demais características físicas da mercadoria eram utilizadas como indicadores da qualidade: quanto mais escuro, mais impuro e menos tratado supunha-se ser o açúcar.

Durante boa parte do século XIX, o chamado "padrão holandês" foi a referência dos mercados para a qualidade do açúcar. Este sistema dividia a gama do açúcar escuro ao totalmente branco em 21 unidades. A maior parte dos relatos, das análises e das estatísticas, contudo, deixa de lado estes detalhes comerciais, adotando indicações genéricas, como açúcar mascavo (ainda contendo melaço), em oposição ao branco (não refinado, mas com baixo teor de melaço), ou ainda açúcar bruto, em oposição ao refinado. A generalização dos processos industriais modernos, a partir da década de 1880 , criou uma distinção clara entre açúcares centrifugados e não-centrifugados, e entre refinados ou brutos.

Não se pode esquecer que o açúcar, seus documentos e estatísticas sempre foram sujeitos à manipulação, por representarem qualidades, quantidades e valores que tiveram - ao serem emitidos - relevante significado econômico para seus donos, pois era com base neles que pagavam fretes, seguros, impostos e vendiam seu produto. Tratava-se não somente de obter vantagens comerciais, mas também de burlar o fisco, que logo aprendeu a taxar mais os açúcares mais valiosos. Assim, expedientes como o escurecimento do açúcar, pela mistura a um mel mais escuro, ou seu embranquecimento, pela sulfitação, fizeram o ganho 
de muitos espertalhões. $O$ assunto passou a ser tratado cientificamente nas décadas finais do século XIX, com a utilização de aparelhos capazes de aferir com precisão o teor de sacarose de cada produto, independentemente de sua cor e aspecto. O comércio do açúcar e suas estatísticas caminhavam para uma maior homogeneidade e para a precisão das técnicas modernas.

Não se pode esquecer da própria confiabilidade dos dados. Moreno Fraginals relata como, entre as décadas de 1820 e 1850, as estatísticas de produção e exportação de açúcar (e de outros produtos) de Cuba eram cuidadosamente preparadas e publicadas, com técnica equiparável à de qualquer país europeu da época. A partir dos anos 1860, contudo, passaram a ser sistematicamente adulteradas, omitindo-se quantidades e deixando-se de publicar informações para favorecer os interesses especulativos dos negociantes coloniais espanhóis. Tais erros chegaram a representar discrepâncias de mais de $40 \%$, quando comparadas às estatísticas correspondentes dos países importadores.

Dentre os aspectos de precisão, devemos incluir as diversas formas de registrar as safras — seja pelo ano-safra (ano n/ano $n+1)$, seja pelo ano-calendário. Não abordaremos mais este detalhe técnico no que segue, muitas vezes citando unicamente o primeiro ano de cada safra, para simplificar a notação.

\section{Ignorância}

Informações sobre o transporte e a importação de açúcar colonial foram as primeiras estatísticas açucareiras disponíveis. Assim, as estimativas iniciais de produção mundial incluíam, no tocante aos países tropicais, somente o volume de açúcar exportado, único sobre o qual havia registros. Ao buscar-se informação sobre o total produzido, esta aproximação gerava erros maiores em países como o Brasil e a Índia, onde existia consumo local mais alto. No caso da Índia, sabe-se que a tradicional produção de açúcar não-centrifugado (gur) é importante há vários séculos, embora sem relevância para o comércio internacional.

Torna-se necessário dar maior atenção à distinção entre açúcares centrifugados ou não a partir do século XX, quando muitas séries passaram a se restringir aos centrifugados, embora diversos países, além da Índia e do Brasil, tenham mantido sua produção não-centrifugada

\footnotetext{
${ }^{*}$ Moreno Fraginals, 1989:305-44.
} 
(México, Filipinas e Japão, entre outros), o que criou uma especificidade adicional para as apresentações estatísticas."

Outra importante omissão "por ignorância" deu-se no início do século XIX, na Europa, com o surgimento da tributação sobre o açúcar de beterraba, o que passou a gerar registros sobre área plantada de beterraba, produção de açúcar e de melaços. Em alguns países europeus, houve discrepâncias entre as estatísticas oficiais e a produção efetiva, pois, nas estatísticas, se tomava a quantidade tributada, sobre a qual havia registro, como o total produzido, mesmo sabendo-se que havia açúcares sobre os quais não incidiam impostos e, portanto, escapavam ao registro. Este problema afetou principalmente os números da Rússia, da Alemanha e da Áustria-Hungria, antes de 1850.

Outra questão que se poderia classificar entre as decorrentes de nossa ignorância é a das abrangências geográficas flutuantes. O principal exemplo desta situação é a Europa, no período da Primeira até a Segunda Guerra Mundial, quando importantes regiões produtoras de beterraba açucareira trocaram regularmente de nome e de soberania, além de verem suas fronteiras encolherem ou incharem, sem que estas mudanças fossem adequadamente registradas para efeitos estatísticos. Nem sempre as séries mundiais cobrindo este período indicam seus critérios específicos de classificação geográfica.

\section{As séries analisadas}

Examinam-se as seguintes séries (Quadro 2), nos seus dados referentes ao período entre 1820 e 1940, cuja abrangência é representada na Figura 1. Estas séries mereceram a confiança de muitos autores. Para ilustrar sua divulgação na historiografia do setor, apresentamos, no Quadro 3, anexo, num apanhado parcial, algumas referências que citam tanto os autores das séries estatísticas analisadas, como outras séries conhecidas, mas não diretamente analisadas aqui..$^{10}$

FAO - Food and Agriculture Organization of the United Nations apresenta para alguns países estatísticas de produção de açúcares não-centrifugados desde 1879 (1960:34-36).

A série USDA cita especificamente as estatísticas de Willett \& Grey, que não analisamos, mas cuja informação numérica podemos considerar estar representada nela. Szmrecsányi (1988) cita as séries de produção mundial de açúcar de cana e de beterraba (1908/09 a 1937/38) de H.Ahlfeld (Tendências do Desenvolvimento e Transformações da Indústria Açucareira Mundial nos últimos 25 anos - Brasil Açucareiro,XVI (6),dez. 1940:23-25),que são arredondamentos dos números apresentados por Deerr 1950 . 
Quadro 2. As séries estatísticas analisadas

\begin{tabular}{|c|c|c|c|}
\hline Série & Período & Publicação & $\begin{array}{l}\text { Referência } \\
\text { bibliográfica }\end{array}$ \\
\hline US Department of Agriculture (USDA) & $1853-1903$ & 1904 & (Rutter, 1904) \\
\hline US Department of Agriculture (USDA) & $1909-1937$ & 1938 & $\begin{array}{l}\text { (Lynsky 1937; } \\
\text { U.S.Department of } \\
\text { Agriculture, 1937) }\end{array}$ \\
\hline Prinsen Geerligs (PG) & $1852-1930$ & 1931 & (Prinsen Geerligs, 1931) \\
\hline Die Deutsche Zuckerindustrie (DDZ) & $1900-1939$ & 1939 & $\begin{array}{l}\text { (Centro Azucarero } \\
\text { Argentino, 1939) }\end{array}$ \\
\hline Noel Deerr (ND) & $1839-1940$ & 1950 & (Deerr, 1950) \\
\hline \multicolumn{4}{|l|}{ Food and Agriculture Organization } \\
\hline of the United Nations (FAO) & $1880-1959$ & 1960 & $\begin{array}{l}\text { (FAO-Food and } \\
\text { Agriculture } \\
\text { Organization of the } \\
\text { United Nations, 1960) }\end{array}$ \\
\hline F.O. Licht (FOL) & $1900-1961$ & 1962 & (F.O. Licht, 1962) \\
\hline International Sugar Council (ISC) & $1810-1962$ & 1963 & $\begin{array}{l}\text { (International Sugar } \\
\text { Council, 1963) }\end{array}$ \\
\hline Moreno Fraginals (MMF) & $1820-1959$ & 1978 & $\begin{array}{l}\text { (Moreno Fraginals, } \\
\text { 1989) }\end{array}$ \\
\hline
\end{tabular}

Fontes: Rutter, F. R. International Sugar Situation. Washington: U.S. Dept. of Agriculture, (Bureau of Statistics Bulletin), v. 30, 1904, 98 pp.; USDA. World Sugar Situation, 1931, apud Lynsky, M. (1938) Sugar Economics, Statistics and Documents. New York: US. Cane Sugar Refiners' Association, 1937,305 pp. Prinsen Geerligs, H. C. Geschiedenis van de Wetgeving op de Beetwortelsuiker. Arasterdam:J.H. de Bussy, 1931,237 pp.; Centro Azucarero Argentino. EstadísticaAzucarera. Buenos Aires v. 1, 1939; Deerr, N. The History of Sugar. London: Chapman \& Hall v. 2, 1959; FAO Food and Agriculture Organization of the United Nations. The World Sugar Economy in Figures 1880-1959. Roma: FAO, 1960,137 pp.; F.O. Licht. Jubiläumsaugabe. Die Weltzuckerwirtschaft 1936-1961. Ratzeburg: F.O.Licht K.G., 1962,178 pp.; International Sugar Council (1963). The World Sugar Economy. Structure and Policies. London: International Sugar Council. v. 1,311, v. II, 1963, 351 pp.; Moreno Fraginals, M. O Engenho. Complexo socioeconômico açucareiro cubano (II). São Paulo: Unesp-Hucitec v. 2+3, 1989, 634 pp.

Figura 1. Abrangência cronológica das séries analisadas

\begin{tabular}{|c|c|c|c|c|c|c|c|c|c|c|c|c|c|}
\hline & 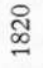 & 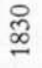 & 웅 & $\begin{array}{l}\text { 으 } \\
\infty \\
\stackrel{-}{-}\end{array}$ & \begin{tabular}{l} 
ᄋ \\
$\infty$ \\
\hdashline
\end{tabular} & 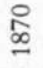 & $\begin{array}{l}\infty \\
\infty \\
\infty \\
\infty\end{array}$ & $\stackrel{\circ}{\infty}$ & 용 & $\frac{0}{2}$ & 욤 & ๙̊ & 옹 \\
\hline 1904 USDA & & & & $\mathrm{x}$ & $\mathrm{x}$ & $\mathrm{x}$ & $\mathrm{x}$ & $\mathrm{x}$ & $\mathrm{x}$ & & & & \\
\hline 1937 USDA & & & & & & & & & & $\mathrm{x}$ & $\mathrm{x}$ & $\mathrm{x}$ & \\
\hline 1938 Pgeerlig & & & & $\mathrm{x}$ & $\mathrm{x}$ & $\mathrm{x}$ & $\mathrm{x}$ & $\mathrm{x}$ & $\mathrm{x}$ & $\mathrm{x}$ & $\mathrm{x}$ & & \\
\hline 1939 DDZ & & & & & & & & & $\mathrm{x}$ & $\mathrm{x}$ & $\mathrm{x}$ & $\mathrm{x}$ & \\
\hline 1950 Ndeerr & & & $\mathrm{x}$ & $\mathrm{x}$ & $\mathrm{x}$ & $\mathrm{x}$ & $\mathrm{x}$ & $\mathbf{x}$ & $\mathrm{x}$ & $\mathrm{x}$ & $\mathrm{x}$ & $\mathrm{x}$ & $\mathrm{x}$ \\
\hline $1960 \mathrm{FAO}$ & & & & & & & $\mathrm{x}$ & $x$ & $\mathrm{x}$ & $\mathrm{x}$ & $\mathrm{x}$ & $\mathrm{x}$ & $\mathrm{x}$ \\
\hline 1962 FOLicht & & & & & & & & & $\mathrm{x}$ & $\mathrm{x}$ & $\mathrm{x}$ & $\mathrm{x}$ & $\mathrm{x}$ \\
\hline 1963 ISCouncil & & & $x$ & $x$ & $\mathrm{x}$ & $\mathrm{x}$ & $\mathrm{x}$ & $\mathbf{x}$ & $\mathrm{x}$ & $\mathrm{x}$ & $\mathrm{x}$ & $\mathrm{x}$ & $\mathrm{x}$ \\
\hline 1978 MMFraginals & $\mathrm{x}$ & $\mathrm{x}$ & $\mathrm{x}$ & $\mathbf{x}$ & $\mathrm{x}$ & $\mathrm{x}$ & $\mathrm{x}$ & $\mathbf{x}$ & $\mathrm{x}$ & $\mathrm{x}$ & $\mathbf{x}$ & $\mathrm{x}$ & $\mathrm{x}$ \\
\hline Séries por década & 1 & 1 & 3 & 5 & 5 & 5 & 6 & 6 & 7 & 8 & 8 & 7 & 5 \\
\hline
\end{tabular}


Quadro 3. Obras que citam os autores das séries estatísticas

\begin{tabular}{|c|c|c|}
\hline Referência & Título & Autor citado \\
\hline (Zeller, 1920) & Der Kampf zwischen Rohr- und Rübenzucker & HP.PG \\
\hline (Henninger, 1927) & Englands Versorgung mit Zucker & $\mathrm{HP}, \mathrm{PG}$ \\
\hline (Pennock, 1935) & $\begin{array}{l}\text { La question du sucre en Europe depuis la } \\
\text { Guerre Mondiale }\end{array}$ & FOL, HP, PG \\
\hline (Reynier, 1936) & Contribution à l'étude de la question des sucres & $\mathrm{FAO}, \mathrm{W} \& \mathrm{G}$ \\
\hline (May, 1937) & Zucker & HR PG \\
\hline (Luy, 1945) & $\begin{array}{l}\text { Le marche mondial du sucre et le problème } \\
\text { de l'économie sucrière suisse }\end{array}$ & $\mathrm{HP}, \mathrm{PG}, \mathrm{W} \& \mathrm{G}$ \\
\hline (Curtin, 1954) & $\begin{array}{l}\text { The British sugar duties and West Indian } \\
\text { prosperiry }\end{array}$ & ND \\
\hline (Lowndes, 1956) & $\begin{array}{l}\text { South Pacific Enterprise. The Colonial Sugar } \\
\text { Ref. Co. Ltd. }\end{array}$ & ND \\
\hline (Timoshenko & & \\
\hline \& Swerling, 1957) & The World's Sugar. Progress and Policy & $\begin{array}{l}\text { FAO, FOL, ND, } \\
\text { PG.W\&G }\end{array}$ \\
\hline (Eisenberg, 1977) & $\begin{array}{l}\text { Modernização sem mudança. A indústria } \\
\text { açucareira em Pernambuco, 1840-1910 }\end{array}$ & $\mathrm{PG}, \mathrm{ND}$ \\
\hline (Hugill, 1978) & Sugar and ali that...A History of Tate \& Lyle & $\mathrm{PG}, \mathrm{ND}$ \\
\hline (Kuuse, 1983) & The Swedish Sugar Company Cardo, 1907-1982 & FAO, FOL, ISC \\
\hline (Mintz, 1985) & Sweetness and Power & ND \\
\hline (Albert \& Graves, 1988) & $\begin{array}{l}\text { The World Sugar Economy in War \& Depression } \\
1914-40\end{array}$ & FAO, ISC, MMF \\
\hline (Abbott, 1990) & Sugar & FOL, ISC, ND \\
\hline (Chalmin, 1990) & $\begin{array}{l}\text { The making of a sugar giant. Tate \& Lyle } \\
\text { 1859-1989 }\end{array}$ & $\begin{array}{l}\text { FOL, ISC, ND, } \\
\quad \text { PG }\end{array}$ \\
\hline (Pérez-López, 1991) & The Economics of Cuban Sugar & ISC, MMF \\
\hline (Hannah \& Spence, 1996) & The International Sugar Trade & FAO, ND \\
\hline Dye, 1998) & Cuban Sugar in the Age of Mass Production & FAO, MMF \\
\hline
\end{tabular}

Siglas das séries: FAO $=$ Food and Agriculture Organization of the United Nations (1960); FOL = F.O. Licht (1962);HP = Paasche, H. (1891) Zuckerinsdustrie und Zuckerhandel der Welt, Jena: Fischer (não analisado); ISC = International Sugar Council (1963); MMF = Moreno Fraginals, M.(1989); ND = Deerr, N. (1950); PG = Prinsen Geerligs, H. C. (1931); W \& G = Willet and Gray's Weekly Statistical Sugar Trade Journal, New York (não analisado).

Fontes: Abbott, G.C. Sugar. London, New York: Routledge, 1990,396 pp.; Albert, B. \& Graves, A. Introduction. In: Albert, B. \& Graves, A. (Ed.). The World Sugar Economy in War and Depression, 1914-40. London: Routledge, 1988, pp.1-25.; Chalmin, P. The making of a Sugar Giant: Tate and Lyle, 1859-1989.London:Harwood Academic Pub., 1990,782 pp;Deerr, N. The History of Sugar. London: Chapman \& Hall, 1959, v. 2; Dye, A. Cuban Sugar in the Age of Mass Production. Stanford: Stanford University Press, 1998, 344 pp.; Eisenberg, P.L. Modernização sem mudança. A indústria açucareira em Pernambuco 1840-1910.Rio de Janeiro: Editora Paz e Terra; Universidade de Campinas, 1977, 294 pp.; F.O. Licht. Jubiläumsaugabe. Die Weltzuckerwirtschaft 1936-1961. Ratzeburg: F.O. Licht K.G., 1962, 178 pp.; FAO - Food and Agriculture Organization of the United Nations. The World Sugar Economy in Figures 1880-1959. Roma: FAO, 1960, 137 pp.; Hannah, AC. \& Spence, D. The International Sugar Trade. Cambridge, UK: Woodhead Publishing Ltd. - ISO, 1996, 246 pp; Henninger, K.. Englands Versorgung mit Zucker seit dem Aufkotmmender kontinentaleuropäischen 


\section{Continuação}

Rübenzuckerindustrie. Berlin: Winckelmann \& Söhne, 1927, 101 pp.; Hugill, A. Sugar and ali that...A History of Tate \& Lyle. London: Gentry Books, 1978, 320 pp.; International Sugar Council. The World Sugar Economy. Structure and Policies. London: International Sugar Council. v.1:311, v. 11:351, 1963 pp.; Kuuse, J. The Swedish Sugar Company Cardo, 1907-1982. Malmö: J.Kuuse-Cardo, 1983, 221 pp.; Lowndes, A.G. Ed. South Pacific Enterprise. The Colonial Sugar Refining Company Limited. Sydney: Angus \& Robertsoned, 1956, 500 pp.; Luy, M. Le Marche mondial du sucre et le problème de l'économie sucrière suisse. Paris: Librairie du Recueil Sirey, 1945, 240 pp.; May, G. Zucker. Grundlagen und Kräfte der Weltmarktentwicklung nach dem Weltkrieg. Leipzig: Bibliographisches Institut AG, 1937, 112 pp.; Mintz, S.W. Sweetness and Power. The Place of Sugar in Modern History. New York: Viking, 1985, 274 pp.; Moreno Fraginals, M. O Engenho. Complexo sócio-econômico açucareiro cubano (II). São Paulo: Unesp-Hucitec v. 2+3, 1989, 634 pp.; Pennock, J.A. La Question du Sucre en Europe depuis laguerre mondiale. Paris: Librairie JB Baillière et Fils, 1935, 255 pp.; Pérez-López, J.F. The Economics of Cuban Sugar. Pittsburg: University of Pittsburg Press, 1991, 313 pp.; Prinsen Geerligs, H.C. Geschiedenis van de Wetgeving op de Beetwortelsuiker. Amsterdam:J.H. de Bussy, 1931, 237 pp.; Reynier, M. Contribution à l'Étude de la Question des Sucres. Paris: Eds. Domat-Montchrestien, 1936, 287 pp.; Timoshenko, V.\& Swerling, B.C. The Worlds Sugar - Progress and Policy. Stanford, Ca: Stanford University Press, 1957, 364 pp.; Zeller, T. Der Kampft zwischen Rohr- und Rübenzucker. Leipzig: K.F.Koehler, Verlag, 1920, 103 pp.

Numa primeira abordagem, podemos comparar as séries quanto às unidades empregadas, aos tipos de açúcares compilados e às suas fontes. O Quadro 4, a seguir, resume estes aspectos.

Podemos resumir as principais particularidades estatísticas das séries sobre produção mundial de açúcar, agrupadas em três períodos, que representam circunstâncias bastante distintas:

1) de 1820 à década de 1880, havia informação muito desigual dos órgãos oficiais nacionais, embora estivessem mais adiantados na Europa e nos Estados Unidos do que nos demais países. A principal informação sobre açúcar de cana ainda era estatística de comércio internacional, deixando de fora o consumo de muitas regiões produtoras. As quantidades de açúcar bruto eram, em geral, apresentadas em adição ao açúcar refinado;

2) nas duas últimas décadas do século XIX, quase todos os países europeus já publicavam estatísticas oficiais incluindo produção de açúcar. Consultores especializados também começaram a se dedicar ao setor (destacando-se o criterioso trabalho de F. O. Licht ${ }^{11}$ ). Múltiplas fontes passaram a ser comparadas, gerando estatísticas mais confiáveis

Após 20 anos como funcionário público, F.O. Licht se estabeleceu por conta própria em 1861. Foi pioneiro na utilização de métodos amostrais para estimar safras ao longo do ano. Suas estimativas (e as estatísticas de produção obtidas) logo adquiriram notoriedade e respeito. Por infelicidade, os arquivos da empresa que manteve seu nome foram totalmente destruídos durante a Guerra de 1939-45. Moreno Fraginals 1989:336-339, F.O.Licht 1962:6-9. 
Quadro 4. Características gerais das séries analisadas

\begin{tabular}{|c|c|c|c|c|c|}
\hline Série & Período & Unidade & Tipo (a) & Fontes citadas & Observações \\
\hline USDA & $1853-1903$ & $\begin{array}{c}\text { Toneladas } \\
\text { longas }\end{array}$ & $\begin{array}{c}\text { "Açúcar } \\
\text { comercial" }\end{array}$ & $\begin{array}{l}\text { Rueb \& Co., } \\
\text { Willett \& Gray, } \\
\text { F.O. Licht, USDA, } \\
\text { J. Helot }\end{array}$ & $\begin{array}{l}\text { Dados anuais (antes de } \\
1888-89 \text { ) são incluídos } \\
\text { como na safra inicia- } \\
\text { da no ano anterior }\end{array}$ \\
\hline USDA & $1909-1937$ & $\begin{array}{l}\text { Toneladas } \\
\text { curtas }\end{array}$ & $\begin{array}{l}\text { Equivalente } \\
\text { açúcar bruto }\end{array}$ & $\begin{array}{l}\text { "Fontes oficiais", } \\
\text { International } \\
\text { Institute of Agri- } \\
\text { culture e fontes } \\
\text { comerciais }\end{array}$ & $\begin{array}{l}\text { Quantidade para a } \\
\text { Índia é total de gur, } \\
\text { sem fazer a equiva- } \\
\text { lência para bruto } \\
\text { (bruto }=60 \% \text { gur) }\end{array}$ \\
\hline $\begin{array}{l}\text { Prinsen } \\
\text { Geerligs }\end{array}$ & $1852-1930$ & $\begin{array}{l}\text { Toneladas } \\
\text { métricas }\end{array}$ & Sem indicação & $\begin{array}{l}\text { H. Paasche, RO. } \\
\text { Licht, Willett \& } \\
\text { Gray e outros }\end{array}$ & \\
\hline DDZ & $1900-1939$ & $\begin{array}{l}\text { Toneladas } \\
\text { métricas }\end{array}$ & $\begin{array}{l}\text { Açúcar } \\
\text { bruto }\end{array}$ & & $\begin{array}{l}\text { Obtivemos esta série } \\
\text { em fonte secundária }\end{array}$ \\
\hline Deerr & $1839-1940$ & $\begin{array}{c}\text { Toneladas } \\
\text { longas ou } \\
\text { métricas }\end{array}$ & Sem menção & $\begin{array}{l}\text { H. Paasche, } \\
\text { Prinsen Geerligs, } \\
\text { F.O. Licht (a } \\
\text { partir de 1930) } \\
\text { e outros }\end{array}$ & $\begin{array}{l}\text { Indica a omissão de } \\
\text { dados anteriores a } \\
\text { certas datas para al- } \\
\text { guns países. Avisa } \\
\text { que não uniformizou } \\
\text { as toneladas }\end{array}$ \\
\hline FAO & $1880-1959$ & $\begin{array}{c}\text { Toneladas } \\
\text { métricas }\end{array}$ & $\begin{array}{l}\text { Equivalente } \\
\text { açúcar bruto, } \\
\text { tel quel em } \\
\text { alguns países }\end{array}$ & $\begin{array}{l}\text { "Fontes oficiais" } \\
\text { de cada país }\end{array}$ & $\begin{array}{l}\text { Separa açúcar } \\
\text { centrifugado e } \\
\text { não-centrifugado }\end{array}$ \\
\hline $\begin{array}{l}\text { FO } \\
\text { Licht }\end{array}$ & $1900-1961$ & Toneladas & $\begin{array}{l}\text { Equivalente } \\
\text { açúcar bruto }\end{array}$ & Não cita fontes & $\begin{array}{l}\text { Indica períodos de } \\
\text { safras distintos para } \\
\text { alguns países. } \\
\text { Separa gur na Índia a } \\
\text { partir de } 1924 / 25\end{array}$ \\
\hline ISC & $1810-1959$ & $\begin{array}{c}\text { Toneladas } \\
\text { métricas }\end{array}$ & $\begin{array}{l}\text { Até 1880: tel } \\
\text { quel. Após } 1880 \text { : } \\
\text { centrifugado, } \\
\text { equivalente bruto }\end{array}$ & $\begin{array}{l}\text { Até } 1880, \mathrm{~N} \text {. } \\
\text { Deerr.Após } 1880 \text { : } \\
\text { fontes oficiais } \\
\text { de cada país }\end{array}$ & $\begin{array}{l}\text { Indicação de países } \\
\text { cujo consumo foi } \\
\text { desprezado.Até } 1880 \text {, } \\
\text { ano calendário; após, } \\
\text { ano-safra }\end{array}$ \\
\hline $\begin{array}{l}\text { Moreno } \\
\text { Fraginals }\end{array}$ & s $1820-1959$ & Toneladas & $\begin{array}{l}\text { Sem indicação } \\
\text { métricas }\end{array}$ & $\begin{array}{l}\text { Sem indicação, } \\
\text { contudo, para açú- } \\
\text { car de beterraba, } \\
\text { até } 1899 \text { dados } \\
\text { idênticos aos de Dee } \\
\text { após, idênticos aos } \\
\text { de F.O. Licht }\end{array}$ & Ver nota (b) \\
\hline
\end{tabular}

Fontes: Indicadas no Quadro 2.

Notas: (a) A expressão tel quel indica a soma de açúcares brutos e refinados, sem cálculos de equivalência de peso. "Equivalente açúcar bruto", ao contrário, indica que foi considerada, no cômputo estatístico, a quantidade de açúcar bruto necessária para produzir cada tonelada de açúcar refinado; 


\section{Continuação}

(b) Todos os dados de Moreno Fraginals para açúcar de beterraba, a partir de 1900 (conforme apresentados na tabela à página 350 , vol. 2 da edição brasileira), estão defasados em um ano, pois o valor de 1899 é repetido em 1900, continuando a série a partir daí corretamente. Como a série, a partir de 1900, é praticamente idêntica à de F.O. Licht, o erro torna-se transparente. Trata-se certamente de descuido do autor (talvez numa tentativa de casar dados de ano calendário com ano-safra?), pois os totais para "Produção total", de 1900 em diante, somam a cada ano os valores indicados na coluna "Cana de açúcar" com os valores do ano anterior para "Beterraba".

Seus dados para "Cana" nos anos de 1900 e 1901, embora não sejam idênticos, são suficientemente próximos para se supor que aconteceu o mesmo tipo de erro também nesta coluna. A defasagem sistemática com os dados de F.O. Licht parece confirmar esta hipótese. Assim, todos os dados a partir de 1901 em "Cana de açúcar" também devem ser adiantados em um ano. Os dados da coluna "Produção total" devem ser recalculados após estas correções. Os valores de nossos Quadros 6, anexos, já incorporam estas retificações.

e abrangentes, principalmente sobre os países plantadores de cana, cuja produção estava usualmente sujeita a menos registros do que os de beterraba;

3) a partir do século XX, fundaram-se diversas entidades internacionais, que agregaram informações sobre produção açucareira. Dentro do escopo da Convenção de Bruxelas, foi criada (1902) uma Comissão Permanente, responsável pela reunião de informações estatísticas. A Liga das Nações (1919) manteve um Departamento Estatístico, que seria, mais adiante, incorporado pela Organização das Nações Unidas. As estatísticas nacionais tornaram-se regulares e mais confiáveis.

\section{Confluências e discrepâncias (1): açúcar de cana, de 1820 a 1879}

Examinemos agora os valores de produção de açúcar de cana, apresentados pelas séries analisadas. Para facilitar a visualização dos gráficos, dividiremos o período total em dois subperíodos: de 1820 a 1879 e de 1880 a 1940 ,o que também corresponde ao recorte cronológico aproximado da evolução das técnicas na produção açucareira.

Analisadas graficamente, as séries apresentam discrepâncias claras no período de 1838 a 1853. A série do International Sugar Council (ISC) indica, neste intervalo, quantidades bastante inferiores às citadas por Deerr e Moreno Fraginals. Por existirem diversos anos nesta série com falhas na informação de muitos países, ajustamos a série do ISC, completando as lacunas, país a país, por interpolação simples. Esta nova série ajustada ainda se mostra bastante inferior às demais, conforme pode ser verificado a seguir, na Figura 2. 
Figura 2. Mundo. Produção de açúcar de cana, segundo várias fontes (escala logarítmica)

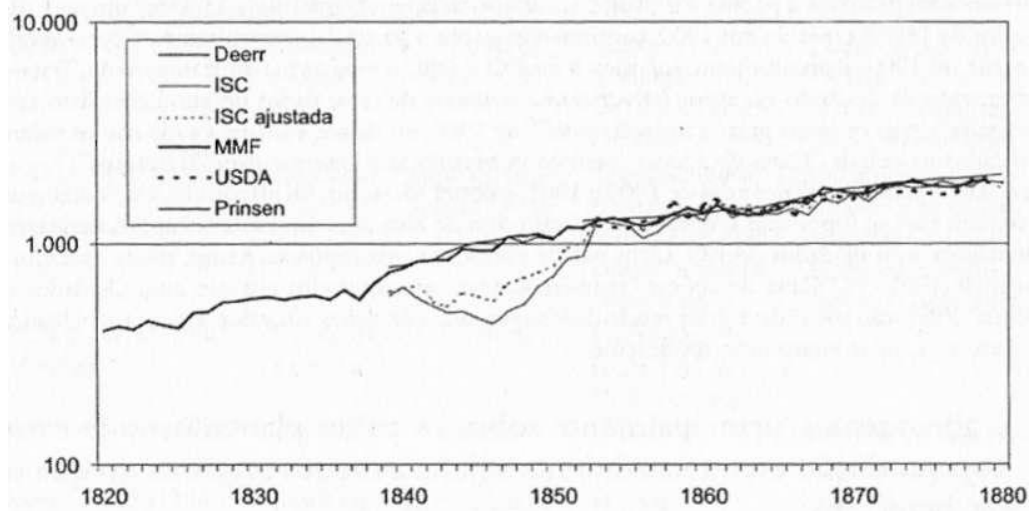

A Figura 3, em seguida, apresenta todas as séries do período em valores relativos aos valores correspondentes de Moreno Fraginals $(=100$ para cada ano).

Figura 3. Mundo. Produção de açúcar de cana, segundo várias fontes - Índice relativo aos valores de Moreno Fraginals (= 100) 1839 a 1880

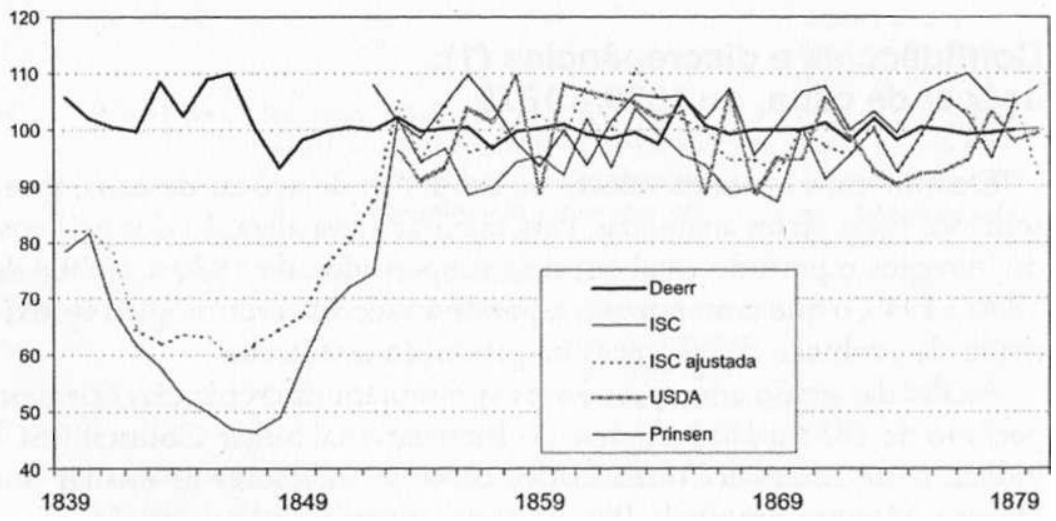

Este último gráfico deixa claras as diferenças em termos percentuais com relação à série de Moreno Fraginals (MMF). A série do ISC (mesmo ajustada) mantém-se, durante toda a década de 1840, mais de 30\% abaixo das quantidades citadas por Deerr e MMF. A série de Deerr, 
por outro lado, fica bastante próxima à de MMF, distanciando-se dela somente em poucos anos. A partir de 1854, todas as séries se mantêm no intervalo de mais ou menos $10 \%$.

Deixando de lado os valores absolutos compilados por cada fonte, o exame de taxas anuais de variação de suas séries (adotando um espaçamento qüinqüenal, para não perder suas flutuações conjunturais) mostra que as diversas séries seguiram em sintonia, nos ciclos de médio prazo (entre 5 e 10 anos). A série do ISC, como já mencionado, não acompanha as demais antes do final da década de 1850 .

Figura 4. Mundo. Produção de açúcar de cana — Variação anual no qüinqüênio anterior (\%)

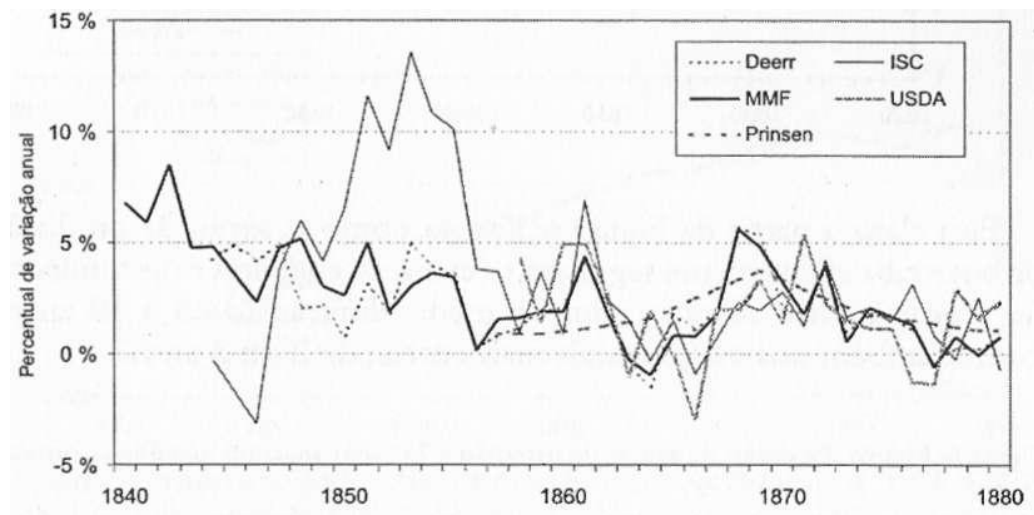

\section{Confluências e discrepâncias (2): açúcar de beterraba, de 1820 a 1879}

As séries de produção do açúcar de beterraba são aparentemente bem mais coesas do que as do de cana, conforme se vê na Figura 5.

Não transparecem no gráfico, contudo, as repetidas discrepâncias entre as séries e a existência de anos em que uma delas se distancia significativamente das demais, o que pode ser aferido por seu afastamento médio da série de MMF, como fizemos anteriormente para o açúcar de cana. A série de Deerr é idêntica à de MMF. A do ISC mostra-se mais próxima da de MMF (somente 2,4\% de afastamento no período de 1839 a 1880), enquanto as beterrabeiras do USDA e de Prinsen Geerligs ficam mais afastadas das de MMF do que ficaram suas séries de cana (4,4\% USDA e -5,0 PG). 
Figura 5. Mundo. Produção de açúcar de beterraba, segundo diversas fontes (escala logarítmica) 1820 a 1880

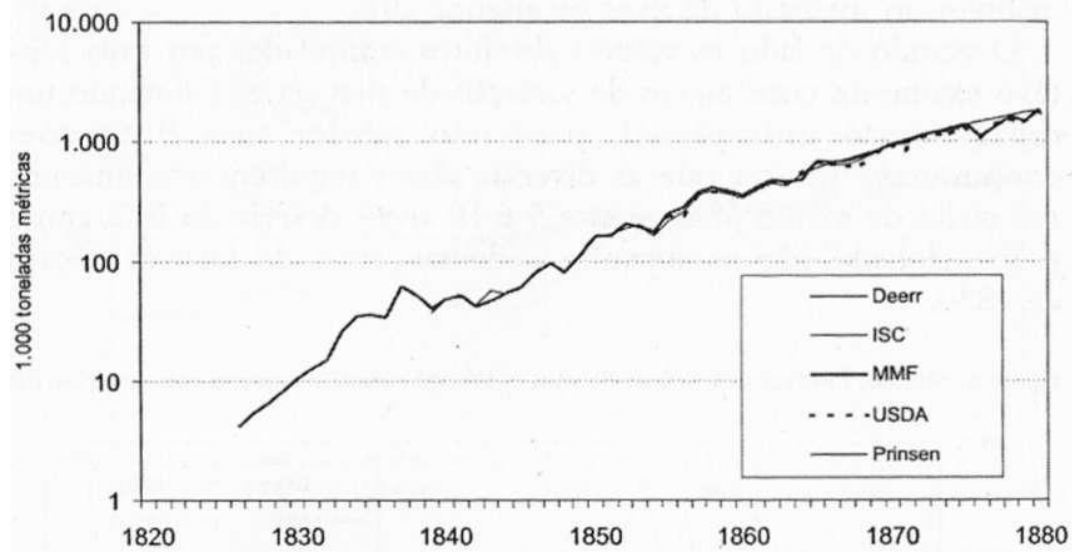

Fica claro, a partir da Figura 6, abaixo, como as séries de produção de beterraba efetivamente seguiram os ciclos ascendentes e descendentes de produção, não só nos ciclos de média duração (de 5 a 10 anos), como também nos conjunturais mais curtos, de 2 ou 3 anos.

Figura 6. Mundo. Produção de açúcar de beterraba - Variação anual no qüinqüênio anterior

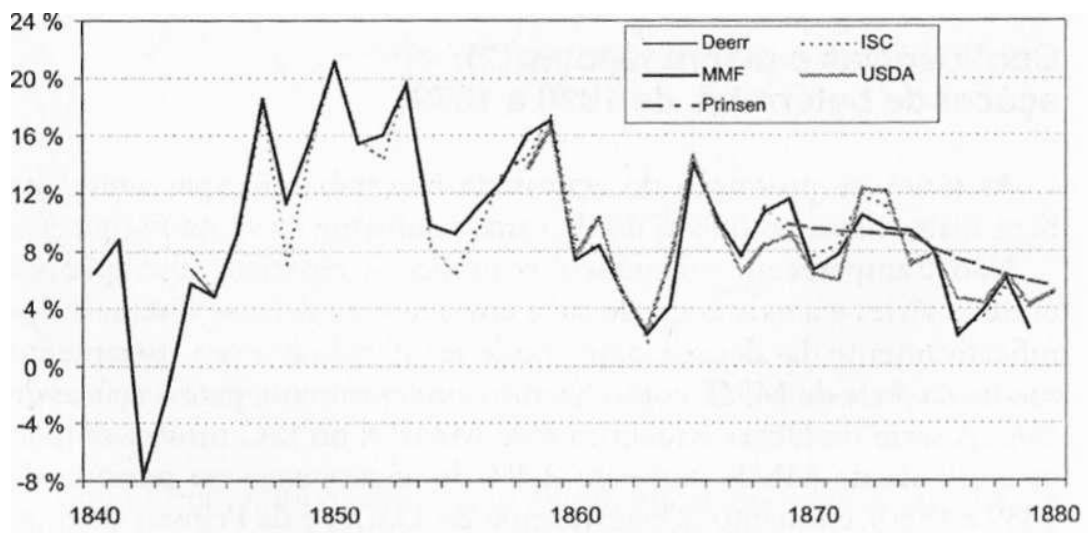




\section{Confluências e discrepâncias (3): açúcar de cana, de 1880 a 1940}

Apresentamos gráfico da evolução de somente 4 das séries analisadas, que têm em comum a particularidade de dar um grande salto no ano de 1900. Deerr explica o salto pela sua inclusão da produção indiana somente naquele ano. Faz menção também à exclusão da produção de diversas regiões do sudeste asiático, que só aos poucos foram incluídas. ${ }^{12}$

Figura 7. Mundo. Produção de açúcar de cana, segundo diversas fontes (escala logarítmica)

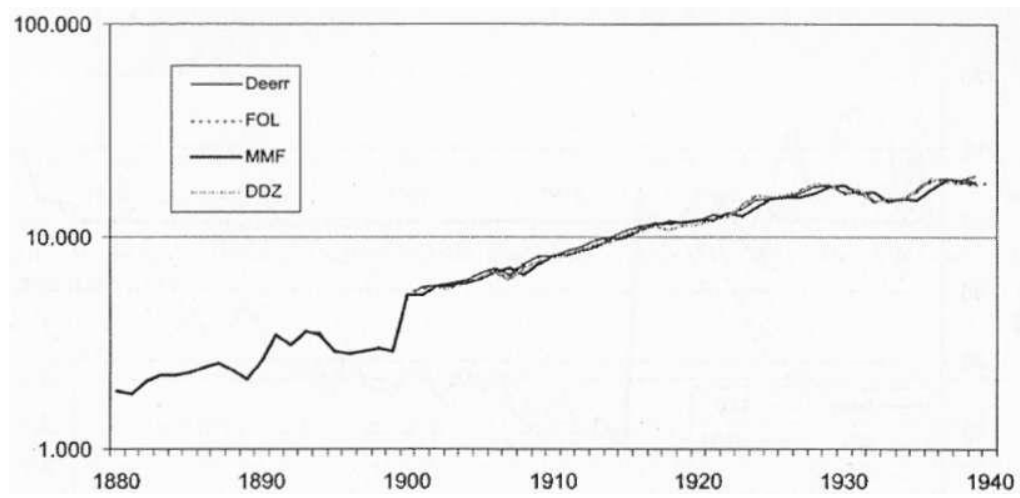

Dada a anterioridade das informações coletadas por F.O. Licht (FOL) e pela revista Die Deutsche Zuckerindustrie (DDZ), supomos que Deerr escolheu acompanhar estas fontes na inclusão da produção de açúcar de qualquer natureza, ao passo que o ISC e Prinsen Geerligs mantiveram suas estatísticas refletindo unicamente a produção de açúcar centrifugado.

Repetindo, para o atual período, a comparação das séries com a de MMF, constata-se que:

a) MMF, Deerr e DDZ mantiveram, após 1900, seus critérios de inclusão regional e de tipo de açúcar;

b) DDZ apresenta omissões relativamente a MMF e Deerr, que se mantêm de 1900 a 1923, passando, na década seguinte (até 1933), a superestimar certas produções (ou a incluir produções que estas séries não consideravam);

Deerr, $1950: 485-486$. 
c) Prinsen Geerligs acompanhou de perto os dados de ISC após 1900;

d) as fortes flutuações de ISC e USDA em torno das estimativas de MMF e Deerr, nos últimos anos do século XIX, reduziram-se sensivelmente após 1900;

e) a discrepância devida à inclusão de açúcar não-centrifugado, entre ISC-PG, de um lado, e MMF-Deerr-DDZ, do outro, foram diminuindo a partir de 1900 (quando atingiram 30\%) até uma faixa média de $15 \%$ entre 1925 e 1940 .

Figura 8. Mundo. Produção de açúcar de cana, segundo várias fontes - Índice relativo aos valores de Moreno Fraginals (= 100) 1880 a 1940

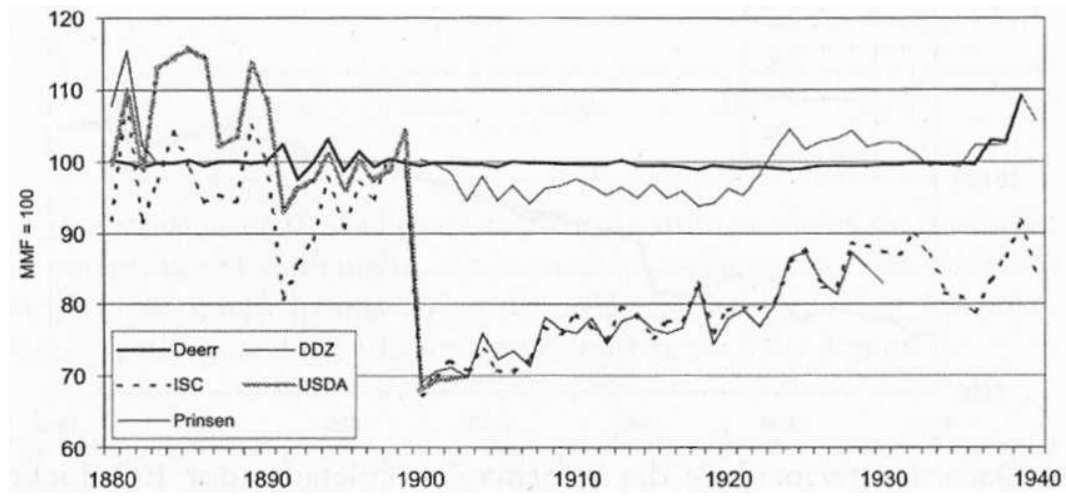

\section{Confluências e discrepâncias (4): açúcar de beterraba, de 1880 a 1940}

As séries sobre produção de açúcar de beterraba são bastante semelhantes, devendo-se destacar a acentuada queda na produção total no período entre 1914 e 1920, que só iria retornar aos níveis pré-guerra em 1930, como mostra a Figura 9, adiante.

Essa Figura mostra que, na maioria dos anos deste período, mesmo durante a Guerra de 1914-18, as diversas séries se mantiveram dentro de uma faixa de mais ou menos 5\%. A queda excepcional na safra de 1888 (1888/89) significa que MMF superestimou, naquele ano, a produção ou, inversamente, que ISC e PG a subestimaram. No período pós-1900, fica claro que MMF inclui regularmente produção que não é computada por PG. 
Figura 9. Mundo. Produção de açúcar de beterraba, segundo diversas fontes (escala logarítmica) $1880-1940$

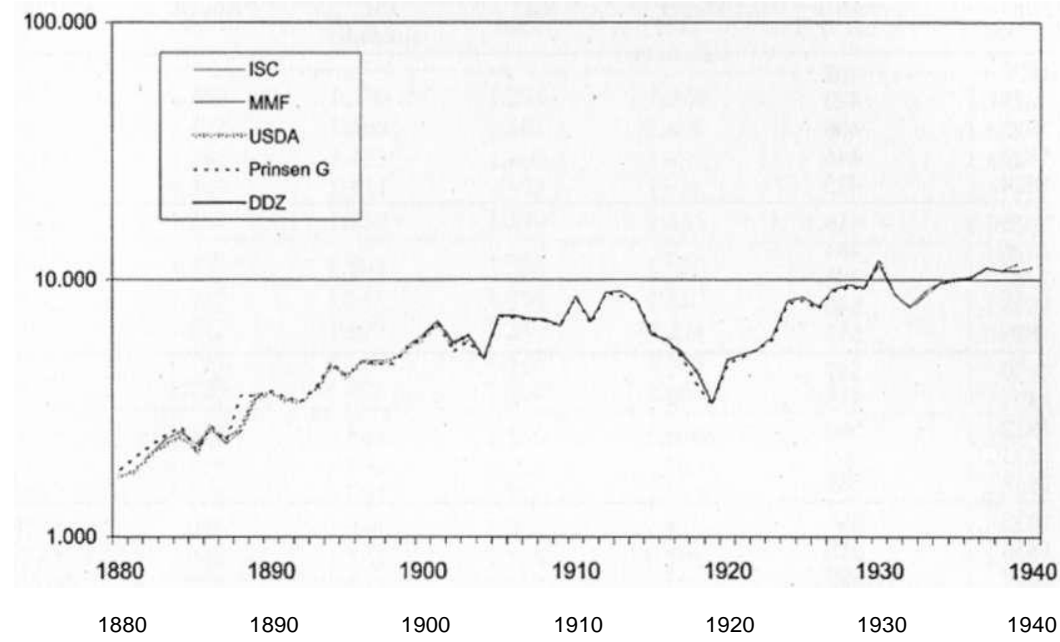

Figura 10. Mundo. Produção de açúcar de beterraba - Índice relativo aos valores de MMF $(=100) \quad 1880-1940$

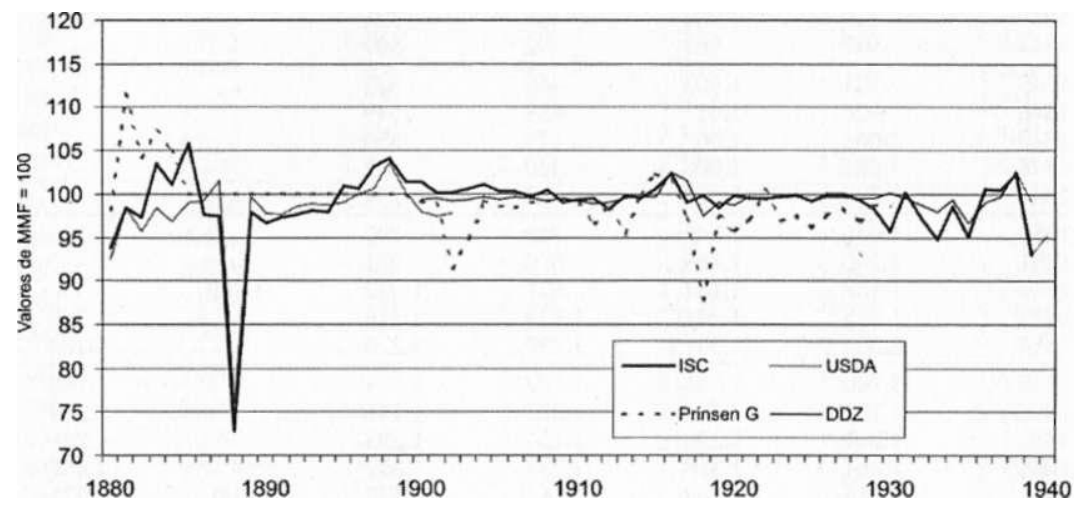

As séries analisadas estão listadas nos Quadro 5 (açúcar de cana) e 6 (açúcar de beterraba), anexos. 
Quadro 5a. Produção mundial de açúcar de cana - Período de 1820 a 1859 (1.000 toneladas métricas)

\begin{tabular}{|c|c|c|c|c|c|c|}
\hline Ano & MMF & Deerr & ISC & $\begin{array}{c}\text { ISC } \\
\text { ajustado }\end{array}$ & Prinsen & USDA \\
\hline 1820 & 402 & - & - & - & - & - \\
\hline 1821 & 423 & - & - & - & - & - \\
\hline 1822 & 408 & - & - & - & - & - \\
\hline 1823 & 446 & - & - & - & - & - \\
\hline 1824 & 425 & - & - & - & - & \\
\hline 1825 & 416 & - & - & - & - & - \\
\hline 1826 & 484 & - & - & - & - & - \\
\hline 1827 & 488 & - & - & - & - & - \\
\hline 1828 & 540 & - & - & - & - & $\overline{-}$ \\
\hline & & - & - & & 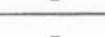 & 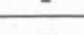 \\
\hline 1830 & 567 & - & - & - & - & - \\
\hline 1831 & 575 & - & - & $\overline{-}$ & - & - \\
\hline 1832 & 560 & - & - & - & - & - \\
\hline 1833 & $\begin{array}{l}569 \\
581\end{array}$ & - & - & - & - & - \\
\hline$\underline{1834}$ & 581 & & & - & & - \\
\hline 1835 & 556 & - & - & - & - & - \\
\hline 1836 & 619 & - & - & - & - & - \\
\hline 1837 & 559 & - & - & - & - & - \\
\hline 1838 & 664 & - & $\overline{-}$ & - & - & - \\
\hline 1839 & 740 & 782 & 579 & 608 & - & - \\
\hline 1840 & 773 & 788 & 631 & 636 & - & - \\
\hline 1841 & 825 & 829 & 566 & 645 & - & - \\
\hline 1842 & 842 & 840 & 521 & 547 & - & - \\
\hline 1843 & 839 & 909 & 484 & 521 & - & - \\
\hline 1844 & 937 & 961 & 492 & 599 & - & - \\
\hline 1845 & 921 & 1.003 & 460 & 582 & - & - \\
\hline 1846 & 926 & 1.017 & 435 & 549 & - & - \\
\hline 1847 & 1.064 & 1.067 & 494 & 659 & - & - \\
\hline 1848 & 1.081 & 1.008 & 530 & 697 & - & - \\
\hline 1849 & 1.089 & 1.070 & 637 & 734 & - & - \\
\hline 1850 & 1.046 & 1.043 & 710 & 797 & - & - \\
\hline 1851 & 1.180 & 1.186 & 850 & 951 & - & - \\
\hline 1852 & 1.168 & 1.167 & 871 & 1.022 & 1.260 & - \\
\hline 1853 & 1.255 & 1.284 & 1.279 & 1.316 & - & 1.200 \\
\hline 1854 & 1.304 & 1.301 & 1.229 & 1.229 & - & 1.184 \\
\hline 1855 & 1.240 & 1.243 & 1.197 & 1.291 & - & 1.158 \\
\hline 1856 & 1.191 & 1.195 & 1.052 & 1.146 & - & 1.239 \\
\hline 1857 & 1.261 & 1.220 & 1.131 & 1.225 & - & 1.280 \\
\hline 1858 & 1.361 & 1.358 & 1.283 & 1.377 & - & 1.487 \\
\hline 1859 & 1.435 & 1.438 & 1.364 & 1.473 & 1.341 & 1.271 \\
\hline 1860 & 1.364 & 1.376 & 1.254 & 1.348 & - & 1.473 \\
\hline 1861 & 1.477 & 1.466 & 1.506 & 1.600 & - & 1.576 \\
\hline 1862 & 1.385 & 1.363 & 1.289 & 1.383 & - & 1.463 \\
\hline 1863 & 1.343 & 1.334 & 1.392 & 1.486 & - & 1.411 \\
\hline 1864 & 1.367 & 1.333 & 1.359 & 1.453 & 1.447 & 1.395 \\
\hline 1865 & 1.420 & 1.506 & 1.356 & 1.450 & - & 1.465 \\
\hline 1866 & 1.535 & 1.544 & 1.436 & 1.530 & - & 1.357 \\
\hline 1867 & 1.513 & 1.499 & 1.340 & 1.434 & - & 1.610 \\
\hline 1868 & 1.761 & 1.759 & 1.575 & 1.669 & - & 1.560 \\
\hline 1869 & 1.729 & 1.728 & 1.507 & 1.601 & 1.741 & 1.636 \\
\hline
\end{tabular}

Fontes: Indicadas no texto. 
Quadro 5b. Produção mundial de açúcar de cana - Período de 1860 a 1899 (1.000 toneladas métricas)

\begin{tabular}{|c|c|c|c|c|c|c|}
\hline Ano & MMF & Deerr & ISC & $\begin{array}{c}\text { ISC } \\
\text { ajustado }\end{array}$ & Prinsen & USDA \\
\hline 1860 & 1.364 & 1.376 & 1.254 & 1.348 & - & 1.473 \\
\hline 1861 & 1.477 & 1.466 & 1.506 & 1.600 & - & 1.576 \\
\hline 1862 & 1.385 & 1.363 & 1.289 & 1.383 & - & 1.463 \\
\hline 1863 & 1.343 & 1.334 & 1.392 & 1.486 & - & 1.411 \\
\hline 1864 & 1.367 & 1.333 & 1.359 & 1.453 & 1.447 & 1.395 \\
\hline 1865 & 1.420 & 1.506 & 1.356 & 1.450 & - & 1.465 \\
\hline 1866 & 1.535 & 1.544 & 1.436 & 1.530 & - & 1.357 \\
\hline 1867 & 1.513 & 1.499 & 1.340 & 1.434 & - & 1.610 \\
\hline 1868 & 1.761 & 1.759 & 1.575 & 1.669 & - & 1.560 \\
\hline 1869 & 1.729 & 1.728 & 1.507 & 1.601 & 1.741 & 1.636 \\
\hline 1870 & 1.662 & 1.662 & 1.666 & 1.666 & - & 1.574 \\
\hline 1871 & 1.676 & 1.697 & 1.526 & 1.627 & - & 1.763 \\
\hline 1872 & 1.842 & 1.805 & 1.756 & 1.763 & - & 1.812 \\
\hline 1873 & 1.811 & 1.848 & 1.808 & 1.815 & - & 1.685 \\
\hline 1874 & 1.916 & 1.883 & 1.773 & 1.773 & 1.903 & 1.729 \\
\hline 1875 & 1.807 & 1.816 & 1.788 & 1.788 & - & 1.666 \\
\hline 1876 & 1.791 & 1.792 & 1.896 & 1.903 & - & 1.656 \\
\hline 1877 & 1.786 & 1.770 & 1.832 & 1.839 & - & 1.689 \\
\hline 1878 & 1.885 & 1.873 & 1.788 & 1.795 & - & 1.935 \\
\hline 1879 & 1.911 & 1.908 & 2.003 & 2.010 & - & 1.873 \\
\hline 1880 & 1.881 & 1.883 & 1.725 & 1.725 & 2.027 & 1.872 \\
\hline 1881 & 1.809 & 1.806 & 1.962 & 1.962 & - & 1.984 \\
\hline 1882 & 2.097 & 2.079 & 1.917 & 1.917 & - & 2.071 \\
\hline 1883 & 2.217 & 2.210 & 2.154 & 2.154 & 2.210 & 2.507 \\
\hline 1884 & 2.229 & 2.225 & 2.322 & 2.322 & 2.225 & 2.552 \\
\hline 1885 & 2.296 & 2.300 & 2.270 & 2.270 & 2.300 & 2.660 \\
\hline 1886 & 2.414 & 2.400 & 2.277 & 2.277 & 2.400 & 2.761 \\
\hline 1887 & 2.543 & 2.541 & 2.425 & 2.425 & 2.541 & 2.600 \\
\hline 1888 & 2.359 & 2.359 & 2.224 & 2.224 & 2.359 & 2.442 \\
\hline 1889 & 2.144 & 2.138 & 2.253 & 2.253 & 2.138 & 2.437 \\
\hline 1890 & 2.600 & 2.597 & 2.601 & 2.601 & 2.597 & 2.824 \\
\hline 1891 & 3.420 & 3.502 & 2.756 & 2.756 & 3.501 & 3.181 \\
\hline 1892 & 3.120 & 3.040 & 2.681 & 2.681 & 3.041 & 2.997 \\
\hline 1893 & 3.567 & 3.561 & 3.176 & 3.176 & 3.561 & 3.476 \\
\hline 1894 & 3.425 & 3.531 & 3.347 & 3.347 & 3.531 & 3.455 \\
\hline 1895 & 2.880 & 2.840 & 2.610 & 2.610 & 2.840 & 2.765 \\
\hline 1896 & 2.799 & 2.842 & 2.706 & 2.706 & 2.842 & 2.797 \\
\hline 1897 & 2.895 & 2.869 & 2.738 & 2.738 & 2.869 & 2.819 \\
\hline 1898 & 2.986 & 2.995 & 2.995 & 2.995 & 2.995 & 2.948 \\
\hline 1899 & 2.889 & 2.881 & 2.896 & 2.896 & 2.881 & 3.008 \\
\hline
\end{tabular}

Fontes: Indicadas no texto. 
Quadro 5c. Produção mundial de açúcar de cana — Período de 1900 a 1940 (1.000 toneladas métricas)

\begin{tabular}{|c|c|c|c|c|c|c|c|c|}
\hline Ano & $\mathrm{MMF}$ & Deerr & ISC & Prinsen & $\begin{array}{l}\text { USDA } \\
\text { (a) }\end{array}$ & $\begin{array}{c}\text { USDA } \\
\text { sem Índia }\end{array}$ & Licht & $\mathrm{DDZ}$ \\
\hline 1900 & 5.285 & 5.253 & 3.563 & 3.646 & 3.588 & - & 5.253 & 5.297 \\
\hline 1901 & (b) 5.775 & 5.763 & 4.042 & 4.079 & 4.015 & - & 5.763 & 5.747 \\
\hline 1902 & 5.857 & 5.844 & 4.228 & 4.164 & 4.079 & - & 5.844 & 5.760 \\
\hline 1903 & 6.057 & 6.035 & 4.288 & 4.234 & 4.245 & - & 6.035 & 5.720 \\
\hline 1904 & 6.293 & 6.265 & 4.626 & 4.776 & - & - & 6.265 & 6.160 \\
\hline 1905 & 6.791 & 6.729 & 4.804 & 4.910 & - & - & 6.729 & 6.416 \\
\hline 1906 & & 7.1 & & & - & - & & 6.894 \\
\hline 1907 & 6.654 & 6.6 & & & - & - & 6.643 & 6.258 \\
\hline 1908 & 7.390 & 7.373 & 5.664 & 5.781 & - & - & 7.372 & 7.108 \\
\hline 1909 & 8.078 & 8.042 & 6.124 & 6.177 & 8.772 & 6.522 & 8.042 & 7.792 \\
\hline 1910 & 8.198 & 8.156 & 6.439 & 6.215 & 8.954 & 6.607 & 8.156 & 7.993 \\
\hline 1911 & & & & & 9.636 & 7.146 & 8. & 8.322 \\
\hline 1912 & 9.017 & 8.969 & 6.7 & 6.7 & 9.885 & 7.288 & 8.9 & 8.585 \\
\hline 1913 & 9.644 & 9.6 & 7.683 & 7.4 & 10.560 & 8.225 & 9.661 & 9.289 \\
\hline 1914 & 9.961 & 9.902 & 7.788 & 7.814 & 10.843 & $8.361^{\circ}$ & 9.902 & 9.447 \\
\hline 1915 & 10.679 & 0611 & 804 & 8.157 & 11.138 & 8.463 & 10.610 & 10.336 \\
\hline 15 & 11.246 & 1 & & & 12.025 & 9.219 & & 10.665 \\
\hline 1917 & 11.807 & 11.7 & 9.160 & 9.0 & 13.417 & 9.935 & 11. & 11.307 \\
\hline 1918 & 11.597 & 11.4 & 9.608 & 9.6 & 12.770 & 10.273 & 11. & 10.872 \\
\hline 1919 & 11.945 & 11.863 & 9.084 & 8.874 & 13.007 & 9.919 & 11.862 & 11.247 \\
\hline 1920 & 12.023 & 11.925 & 9.5 & 9.367 & 12.905 & 0.342 & 5 & 11.562 \\
\hline 1921 & 12.861 & 740 & 10.233 & 10.1 & 13.890 & 11.234 & 40 & 12.235 \\
\hline 1922 & 12.611 & 12.500 & 9.997 & 9.6 & 13.726 & 10.632 & 12. & 12.365 \\
\hline 1923 & 13.645 & 13.520 & 10.979 & 10.9 & 14.949 & 11.578 & 13. & 13.867 \\
\hline 1924 & 15.089 & 14.906 & 12.951 & 13.044 & 16.339 & 13.752 & 14.906 & 15.770 \\
\hline 1925 & 15.305 & 15.141 & 13.42 & 13 & 16.980 & 13.955 & 15 & 15.570 \\
\hline 1926 & 15.412 & & & 12. & 17.036 & 13.717 & & 15.826 \\
\hline 1927 & 16.066 & 15.953 & 13.250 & 13.078 & 17.700 & 14.431 & 15.953 & 16.572 \\
\hline 1928 & 17.302 & 17.188 & 15.320 & 15.103 & 18.718 & 15.971 & 17.188 & 18.053 \\
\hline 1929 & 17.484 & 17.382 & 15.430 & 14.885 & 18.855 & 16.059 & 17.382 & 17.832 \\
\hline 1930 & 16.023 & 15.942 & 13.969 & 13.291 & 17.548 & 14.268 & 15.942 & 16.431 \\
\hline 1931 & 16.287 & 16 & 14.1 & - & 18.196 & 14.158 & 16.216 & 16.710 \\
\hline 1932 & 14.788 & 14.742 & 13.2 & - & 17.018 & 12.267 & 14.742 & 14.970 \\
\hline 1933 & 15.152 & 15.113 & 13.171 & - & 17.403 & 12.428 & 15.113 & 15.044 \\
\hline 1934 & 14.911 & 14.842 & 12.155 & - & 17.027 & 11.804 & 14.842 & 14.869 \\
\hline 1935 & 16.631 & 16.598 & 13.427 & - & 18.977 & 12.980 & 16.598 & 16.502 \\
\hline 1936 & & & & - & 21.573 & & & 18.878 \\
\hline 1937 & & & & - & 21.685 & 15.013 & 18.191 & 18.637 \\
\hline & 17.964 & & & - & - & - & 17.910 & 18.383 \\
\hline 1939 & 17.760 & & 16.264 & - & - & - & 18.731 & 18.785 \\
\hline 1940 & 18.245 & 19.255 & 15.268 & - & - & - & 18.218 & \\
\hline
\end{tabular}

(U.S.Department of Agriculture 1937) listadas em (Lynsky 1937). (b) Suprimimos a quantidade referente ao ano de 1901 por estar repetindo a de 1900. Os anos seguintes foram todos adiantados em um ano, passando a acompanhar de perto as flutuações da série de F.O. Licht, o que evidencia o erro na tabela original de Moreno Fraginals. 
Quadro 6a. Produção mundial de açúcar de beterraba - Período de 1820 a 1859 (1.000 toneladas métricas)

\begin{tabular}{|c|c|c|c|c|c|c|c|}
\hline Ano & MMF & Deerr & ISC & USDA & Prinsen & Licht & DDZ \\
\hline 1820 & - & - & - & - & - & - & - \\
\hline 1821 & - & - & - & - & - & - & - \\
\hline 1822 & - & - & - & - & - & - & - \\
\hline 1823 & - & - & - & - & - & - & - \\
\hline 1824 & - & - & - & - & - & - & - \\
\hline 1825 & & & - & - & - & - & \\
\hline 1826 & 4 & - & - & - & - & - & - \\
\hline 1827 & 5 & - & - & - & - & - & - \\
\hline 1828 & 6 & - & - & - & - & - & - \\
\hline 1829 & 8 & - & - & - & - & - & - \\
\hline 1830 & 11 & - & - & - & - & & - \\
\hline 1831 & 13 & - & - & - & - & - & - \\
\hline 1832 & - 15 & - & - & - & & - & \\
\hline 1833 & 26 & - & - & - & - & - & - \\
\hline 1834 & 35 & - & - & - & - & - & - \\
\hline 1835 & 35 & - & - & - & - & - & - \\
\hline 1836 & 34 & - & - & - & - & - & - \\
\hline 1837 & 62 & - & - & - & - & - & - \\
\hline 1838 & 52 & - & - & - & - & - & - \\
\hline 1839 & 40 & 39 & 37 & - & - & - & - \\
\hline 1840 & 48 & 48 & 48 & & - & - & \\
\hline 1841 & 51 & 51 & 51 & - & - & - & - \\
\hline 1842 & 41 & 41 & 42 & - & - & - & \\
\hline 1843 & 47 & 47 & 57 & - & - & - & - \\
\hline 1844 & 54 & 54 & 54 & - & - & - & - \\
\hline 1845 & 61 & 61 & 61 & - & & - & - \\
\hline 1846 & 80 & 80 & 79 & - & - & - & - \\
\hline 1847 & 96 & 96 & 96 & - & - & - & - \\
\hline 1848 & 80 & 80 & 80 & - & - & - & - \\
\hline 1849 & 111 & 111 & 109 & - & - & - & - \\
\hline 1850 & 159 & 159 & 159 & - & & - & - \\
\hline 1851 & 164 & 164 & 164 & - & - & - & - \\
\hline 1852 & 203 & 203 & 188 & - & 203 & - & - \\
\hline 1853 & 195 & 195 & $1 \%$ & 198 & - & - & _ \\
\hline 1854 & 176 & 176 & 163 & 176 & - & - & - \\
\hline 1855 & 247 & 247 & 217 & 233 & - & - & - \\
\hline 1856 & 277 & 277 & 259 & 246 & - & - & - \\
\hline 1857 & 370 & 370 & 350 & 356 & - & - & _ \\
\hline 1858 & 410 & 410 & 388 & 377 & - & - & - \\
\hline 1859 & 388 & 388 & 363 & 377 & 452 & - & - \\
\hline
\end{tabular}

Fontes: Indicadas no texto. 
Quadro 6b. Produção mundial de açúcar de beterraba - Período de 1860 a 1899 (1.000 toneladas métricas)

\begin{tabular}{|c|c|c|c|c|c|c|c|}
\hline Ano & MMF & Deerr & ISC & USDA & Prinsen & Licht & DDZ \\
\hline 1860 & 352 & 352 & 332 & 340 & - & - & - \\
\hline 1861 & 414 & 414 & 384 & 399 & - & - & - \\
\hline 1862 & 475 & 475 & 443 & 451 & - & - & - \\
\hline 1863 & 457 & 457 & 422 & 429 & - & - & - \\
\hline 1864 & 475 & 475 & 530 & 532 & 530 & - & - \\
\hline 1865 & 681 & 681 & 649 & 669 & - & - & - \\
\hline 1866 & 672 & 672 & 627 & 634 & - & - & - \\
\hline 1867 & 687 & 687 & 640 & 619 & - & - & \\
\hline 1868 & 760 & 760 & 709 & 638 & - & - & - \\
\hline 1869 & 821 & 821 & 831 & 820 & 846 & - & - \\
\hline 1870 & 939 & 939 & 940 & 913 & - & - & - \\
\hline 1871 & 977 & 977 & 940 & 846 & - & - & - \\
\hline 1872 & 1.129 & 1.129 & 1.129 & 1.107 & - & - & - \\
\hline 1873 & 1.199 & 1.199 & 1.198 & 1.128 & - & - & - \\
\hline 1874 & 1.285 & 1.285 & 1.185 & 1.147 & 1.303 & - & - \\
\hline 1875 & 1.377 & 1.377 & 1.363 & 1.330 & - & & - \\
\hline 1876 & 1.085 & 1.085 & 1.067 & 1.067 & - & - & - \\
\hline 1877 & 1.359 & 1.359 & 1.335 & 1.376 & - & - & - \\
\hline 1878 & 1.616 & 1.616 & 1.563 & 1.525 & - & - & - \\
\hline 1879 & 1.459 & 1.459 & 1.462 & 1.408 & - & - & - \\
\hline 1880 & 1.857 & 1.857 & 1.742 & 1.719 & 1.821 & - & - \\
\hline 1881 & 1.832 & 1.832 & 1.803 & 1.803 & - & - & - \\
\hline 1882 & 2.173 & 2.173 & 2.114 & 2.080 & - & - & - \\
\hline 1883 & 2.323 & 2.323 & 2.403 & 2.287 & 2.485 & - & - \\
\hline 1884 & 2.550 & 2.550 & 2.577 & 2.467 & 2.679 & - & - \\
\hline 1885 & 2.172 & 2.172 & 2.297 & 2.151 & 2.172 & - & - \\
\hline 1886 & 2.687 & 2.687 & 2.623 & 2.665 & 2.687 & - & - \\
\hline 1887 & 2.367 & 2.367 & 2.307 & 2.404 & 2.367 & - & - \\
\hline 1888 & 3.556 & 3.556 & 2.589 & 2.700 & 3.556 & & - \\
\hline 1889 & 3.537 & 3.537 & 3.463 & 3.522 & 3.537 & - & - \\
\hline 1890 & 3.680 & 3.680 & 3.559 & 3.598 & 3.680 & - & - \\
\hline 1891 & 3.481 & 3.481 & 3.384 & 3.397 & 3.481 & - & - \\
\hline 1892 & 3.381 & 3.381 & 3.302 & 3.333 & 3.381 & - & - \\
\hline 1893 & 3.833 & 3.833 & 3.760 & 3.787 & 3.833 & - & - \\
\hline 1894 & 4.726 & 4.726 & 4.626 & 4.662 & 4.726 & - & - \\
\hline 1895 & 4.221 & 4.221 & 4.258 & 4.180 & 4.221 & - & - \\
\hline 1896 & 4.802 & 4.802 & 4.831 & 4.799 & 4.802 & - & - \\
\hline 1897 & 4.695 & 4.695 & 4.842 & 4.720 & 4.695 & - & - \\
\hline 1898 & 4.690 & 4.690 & 4.880 & 4.858 & 4.690 & - & - \\
\hline 1899 & 5.411 & 5.411 & 5.489 & 5.417 & 5.411 & - & - \\
\hline
\end{tabular}

Fontes: Indicadas no texto. 
Quadro 6c. Produção mundial de açúcar de beterraba — Período de 1900 a 1940 (1.000 toneladas métricas)

\begin{tabular}{|c|c|c|c|c|c|c|c|}
\hline Ano & MMF & Deerr & ISC & $\operatorname{USDA}(\mathrm{a})$ & Prinsen & Licht & $\mathrm{DDZ}$ \\
\hline 1900 & 6.006 & 6.006 & 6.090 & 5.878 & 5.944 & 6.006 & 5.963 \\
\hline 1901 & 6.881 & 6.881 & 6.891 & 6.709 & 6.801 & 6.881 & 6.846 \\
\hline 1902 & 5.700 & 5.700 & 5.709 & 5.570 & 5.209 & 5.700 & 5.649 \\
\hline 1903 & 6.067 & 6.067 & 6.106 & 5.884 & 5.746 & 6.067 & 6.029 \\
\hline 1904 & 4.920 & 4.920 & 4.973 & - & 4.878 & 4.920 & 4.902 \\
\hline 1905 & 7.274 & 7.274 & 7.298 & - & 7.173 & 7.274 & 7.221 \\
\hline 1906 & 7.225 & 7.245 & 7.248 & - & 7.108 & 7.225 & 7.200 \\
\hline 1907 & 7.063 & 7.063 & 7.036 & - & 6.995 & 7.063 & 7.025 \\
\hline 1908 & 6.986 & 6.986 & 7.015 & - & 6.928 & 6.986 & 6.927 \\
\hline 1909 & 6.648 & 6.648 & 6.581 & 6.494 & 6.589 & 6.648 & 6.619 \\
\hline 1910 & -8.668 & 8.668 & 8.608 & 8.132 & 8.561 & 8.668 & 8.593 \\
\hline 1911 & 6.947 & 6.947 & 6.907 & 6.610 & 6.711 & 6.947 & 6.869 \\
\hline 1912 & 9.039 & 9.039 & 8.885 & 8.751 & 8.891 & 9.039 & 8.946 \\
\hline 1913 & 9.054 & 9.054 & 9.035 & 8.631 & 8.634 & 9.054 & 9.002 \\
\hline 1914 & 8.312 & 8.312 & 8.275 & 8.095 & 8.306 & 8.312 & 8.288 \\
\hline 1915 & 6.111 & 6.110 & 6.144 & 5.994 & 6.252 & 6.111 & 6.089 \\
\hline 1916 & 5.685 & 5.865 & 5.819 & 4.842 & 5.772 & 5.865 & 5.825 \\
\hline 1917 & 5.153 & 5.153 & 5.105 & 4.992 & 5.009 & 5.153 & 5.235 \\
\hline 1918 & 4.428 & 4.428 & 4.417 & 4.108 & 3.883 & 4.428 & 4.312 \\
\hline 1919 & 3.350 & 3.350 & 3.298 & 3.312 & 3.259 & 3.350 & 3.315 \\
\hline 1920 & 4.906 & 4.906 & 4.898 & 4.827 & 4.685 & 4.906 & 4.843 \\
\hline 1921 & 5.130 & 5.130 & 5.105 & 5.009 & 4.985 & 5.130 & 5.108 \\
\hline 1922 & 5.357 & 5.357 & 5.333 & 5.215 & 5.370 & 5.357 & 5.324 \\
\hline 1923 & 6.059 & 6.059 & 6.034 & 5.905 & 5.862 & 6.059 & 6.048 \\
\hline 1924 & 8.296 & 8.296 & 8.279 & 8.082 & 8.094 & 8.296 & 8.299 \\
\hline 1925 & 8.618 & 8.618 & 8.547 & 8.195 & 8.290 & 8.617 & 8.543 \\
\hline 1926 & 7.896 & 7.896 & 7.896 & 7.606 & 7.705 & 7.896 & 7.872 \\
\hline 1927 & 9.165 & 9.165 & 9.161 & 8.834 & 9.024 & 9.165 & 9.137 \\
\hline 1928 & 9.613 & 9.613 & 9.549 & 9.282 & 9.327 & 9.613 & 9.561 \\
\hline 1929 & 9.349 & 9.249 & 9.185 & 9.098 & 9.233 & 9.359 & 9.301 \\
\hline 1930 & 11.911 & 11.911 & 11.398 & 11.097 & 11.739 & 11.921 & 11.923 \\
\hline 1931 & 8.782 & 8.782 & 8.797 & 8.335 & - & 8.792 & 8.741 \\
\hline 1932 & 7.994 & 7.994 & 7.769 & 7.608 & - & 8.004 & 7.893 \\
\hline 1933 & 9.160 & 9.160 & 8.673 & 8.713 & - & 9.170 & 8.966 \\
\hline 1934 & 9.792 & 9.792 & 9.653 & 9.513 & - & 9.802 & 9.734 \\
\hline 1935 & 10.430 & 10.430 & 9.909 & 9.695 & - & 10.440 & 10.088 \\
\hline 1936 & 10.233 & 10.233 & 10.295 & 9.977 & - & 10.226 & 10.136 \\
\hline 1937 & 11.082 & 11.194 & 11.135 & 10.973 & - & 11.082 & 11.040 \\
\hline 1938 & 10.562 & 10.225 & 10.807 & - & - & 10.562 & 10.836 \\
\hline 1939 & 11.622 & 11.117 & 10.811 & - & - & 11.622 & 11.532 \\
\hline 1940 & 11.684 & 11.244 & 11.126 & - & - & 11.684 & - \\
\hline
\end{tabular}

Fontes: Indicadas no texto.

Nota: (a) A série do USDA até 1903 é de Rutter 1904; as séries para 1909-1938 são do U.S. Department of Agriculture 1937, listadas em Lynsky, 1937. 


\section{Conclusões}

As diversas séries estatísticas analisadas acompanharam a evolução da produção açucareira mundial, inicialmente incluindo qualquer açúcar de que se tivesse notícia, indicando unicamente a distinção quanto à sua origem, se de cana ou de beterraba. A medida que o refino e seu comércio se tornaram mais importantes, surgiram menções a açúcares brutos e refinados (ou, ao contrário, à não distinção entre eles).A partir do final do século XIX, nova distinção passa a ser feita, entre açúcares centrifugados e não-centrifugados, embora as estatísticas (com exceção de ISC e F.O. Licht) não fizessem menção expressa ao tipo de açúcar compilado. A partir do início do século $\mathrm{XX}$, os açúcares com baixa concentração de sacarose, em decorrência de processos antiquados de produção, passam a constar de estatísticas separadas, sob o título de "não-centrifugado" ou gur.

Por outro lado, as fontes primárias para a construção de estatísticas evoluíram dos relatos comerciais esporádicos, compilados por uma seqüência de agentes espalhados pelo mundo, para as pesquisas sistemáticas das redes oficiais de organismos estatísticos nacionais e internacionais.

$\mathrm{Na}$ pesquisa sobre produção açucareira, a multiplicidade de fontes secundárias, principalmente a partir do final do século XIX, dificulta o reconhecimento das limitações de cada série, cuidado preliminar para serem utilizadas com menores chances de erros conceituais.

Todas as séries podem ser úteis a determinado objetivo. A simples apresentação de uma estatística, contudo, não expõe um fato histórico; é preciso que ela seja "decodificada", sustentando uma argumentação historiográfica. Procurou-se mostrar que, apesar das dificuldades de pesquisa e de identificação de origem, é possível analisar o conteúdo das séries estatísticas, gerando um instrumento mais seguro para a análise histórica.

\section{Referências bibliográficas}

Abbott, George C. Sugar. London, New York: Routledge, 1990.

Albert, Bill \& Adrian Graves. Introduction. The World Sugar Economy in War and Depression, 1914-40. B. Albert \& A. Graves. London: Roudedge, 1988, p. 1-25.

Centro Azucarero Argentino. Estadística Azucarera.Buenos Aires, 1939.

Chalmin, Philippe. The making of a Sugar Giant: Tate and Lyle, 1859-1989. London: Harwood Academic Pub. [1983], 1990.

Curtin, Philip D. The British Sugar Duties and West Indian Prosperity. The Journal of Economic History, 1954,14(2): 157-64. 
Deerr, Noel. The History of Sugar. London: Chapman \& Hall, 1950.

Dye, Alan. Cuban Sugar in the Age of Mass Production. Stanford: Stanford University Press, 1998 .

Eisenberg, Peter L. Modernização sem mudança.A indústria açucareira em Pernambuco 18401910. Rio de Janeiro: Editora Paz e Terra; Universidade de Campinas, 1977.

F.O. Licht.Jubiläumsaugabe. Die Weltzuckerwirtschaft 1936-1961. Ratzeburg: F.O. Licht K.G, 1962 .

FAO - Food and Agriculture Organization of the United Nations. The World Sugar Economy in Figures 1880-1959. Roma: FAO, 1960.

Hannah, A. C. \& Donald Spence. The International Sugar Trade. Cambridge, UK: Woodhead Publishing Ltd. - ISO, 1996.

Henninger, Kurt. Englands Versorgung mit Zucker seit dem Aufkommender kontinentaleuropàischen Rubenzukerindustrie.Berlin: Winckelmann \& Söhne, 1927.

Hugill, Antony. Sugar and all that. ..A History of Tate \& Lyle. London: Gentry Books, 1978.

International Sugar Council. The World Sugar Economy. Structure and Policies. London: International Sugar Council, 1963.

Kuuse, Jan. The Swedish Sugar Company Cardo, 1907-1982.Malmö:J.Kuuse-Cardo,

1983.

Lowndes,A.G. (Ed.). South Pacific Enterprise.The Colonial Sugar Refining Company Limited. Sydney: Angus \& Robertson, 1956.

Luy, Marcel. Le Marché mondial du sucre et le problème de l'économie sucrière suisse. Paris: Librairie du Recueil Sirey, 1945.

Lynsky, Myer. Sugar Economics, Statistics and Documents. New York: US Cane Sugar Refiners'Association, 1937.

Martin, Olivier. Da estatística política à sociologia estatística. Desenvolvimento e transformações da análise estatística da sociedade (séculos XVII-XIX). Revista Brasileira de História 2001 21(41): 13-34.

May, Gerd. Zucker. Grundlagen und Kräfte der Weltmarktentwicklung nach dem Weltkrieg. Leipzig: Bibliographisches Institut AG, 1937.

McCusker,JohnJ.Weights and Measures in the Colonial SugarTrade: the gallon and the pound and their international equivalents. William and Mary Quarterly 3rd series, 1973 $30(4): 599-624$.

Mintz, Sidney W. Sweetness and Power. The Place of Sugar in Modern History. New York: Viking-Elisabeth Sifton Books, 1985.

Moreno Fraginals, Manuel. O Engenho. Complexo sócio-econâmico açucareiro cubano (II). São Paulo: Unesp-Hucitec, 1989.

Pennock.J.A. La Question du Sucre en Europe depuis la guerre mondiale. Paris: Librairie JB Baillière et Fils, 1935 .

Pérez-López, J.F. The Economics of Cuban Sugar. Pittsburg: University of Pittsburg Press, 1991.

Prinsen Geerligs, H.C. Geschiedenis van de Wetgeving op de Beetwortelsuiker. Amsterdam: J.H. de Bussy, 1931 . 
Prinsen Geerligs, H.C. \& R.J. Prinsen Geerligs. Cane Sugar Production 1912-1937. London: Norman Rodger, 1938.

Reynier, Maurice. Contribution à l'Étude de la Question des Sucres. Paris: Eds. DomatMontchrestien, 1936.

Rutter, Frank R. International Sugar Situation.Washington: U.S. Dept. of Agriculture, 1904. Szmrecsányi, Tamás. 1914-1939 crescimento e crise da agroindústria açucareira do Brasil. Revista Brasileira de Ciências Sociais 1988 3(7): 42-68.

Timoshenko, Vladimir \& Boris C. Swerling. The World's Sugar - Progress and Policy. Stanford, Ca: Stanford University Press, 1957.

U.S.Department of Agriculture. World Sugar Situation. 1937. Washington DC: USDA, 1937.

Zeller,T. Der Kampft zwischen Rohr- und Rübenzucker. Leipzig: K. F.Koehler,Verlag, 1920. 